\title{
Unil
}

UNIL | Université de Lausanne

Unicentre

$\mathrm{CH}-1015$ Lausanne

http://serval.unil.ch

Year : 2018

\section{Magnetic resonance imaging of fetal pelvic cysts}

\author{
Archontaki Styliani
}

Archontaki Styliani , 2018, Magnetic resonance imaging of fetal pelvic cysts

Originally published at : Thesis, University of Lausanne

Posted at the University of Lausanne Open Archive http://serval.unil.ch

Document URN : urn:nbn:ch:serval-BIB_92B86D371BF19

\section{Droits d'auteur}

L'Université de Lausanne attire expressément l'attention des utilisateurs sur le fait que tous les documents publiés dans I'Archive SERVAL sont protégés par le droit d'auteur, conformément à la loi fédérale sur le droit d'auteur et les droits voisins (LDA). A ce titre, il est indispensable d'obtenir le consentement préalable de l'auteur et/ou de l'éditeur avant toute utilisation d'une oeuvre ou d'une partie d'une oeuvre ne relevant pas d'une utilisation à des fins personnelles au sens de la LDA (art. 19, al. 1 lettre a). A défaut, tout contrevenant s'expose aux sanctions prévues par cette loi. Nous déclinons toute responsabilité en la matière.

\section{Copyright}

The University of Lausanne expressly draws the attention of users to the fact that all documents published in the SERVAL Archive are protected by copyright in accordance with federal law on copyright and similar rights (LDA). Accordingly it is indispensable to obtain prior consent from the author and/or publisher before any use of a work or part of a work for purposes other than personal use within the meaning of LDA (art. 19, para. 1 letter a). Failure to do so will expose offenders to the sanctions laid down by this law. We accept no liability in this respect. 


\section{Unil}

UNIL | Université de Lausanne

\section{Ecole doctorale}

UNIVERSITÉ DE LAUSANNE - FACULTÉ DE BIOLOGIE ET DE MÉDECINE

Département de radiologie diagnostique et interventionnelle,CHUV

Service de radiologie

\section{Magnetic resonance imaging of fetal pelvic cysts}

THESE

préparée sous la direction de Docteure Léonor Alamo

et présentée à la Faculté de biologie et de médecine de I'Université de Lausanne pour l'obtention du grade de

DOCTEUR EN MEDECINE

par

Styliani Archontaki

Médecin diplômée Grèce

Originaire de Crète 


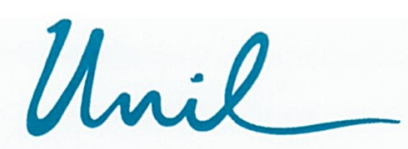

UNIL | Université de Lausanne

Faculté de biologie et de médecine

\section{Ecole Doctorale Doctorat en médecine}

\section{Imprimatur}

Vu le rapport présenté par le jury d'examen, composé de

Directeur de thèse Madame la Docteure Leonor Trinidad Alamo Mestre

Co-Directeur de thèse

Expert

Madame la Docteure Sylviane Hanquinet

Vice-Directeur de

l'Ecole doctorale

Monsieur le Professeur John Prior

la Commission MD de l'Ecole doctorale autorise l'impression de la thèse de

\section{Madame Styliani ARCHONTAKI}

intitulée

Magnetic resonance imaging of fetal pelvic cysts

Lausanne, le 20 septembre 2018

pour Le Doyen

de la Faculté de Biologije et de Médecine

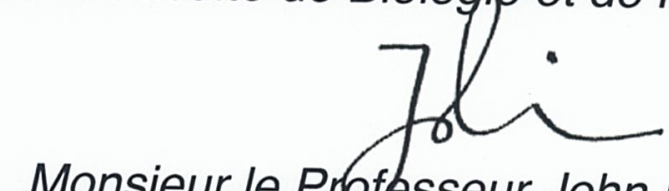

Monsieur le Professeur John Prior

Vice-Directeur de l'Ecole doctorale 


\section{RESUME DE THESE}

Nous présentons une étude rétrospective des pathologies kystiques pelviennes fœtales basée sur des cas étudiés dans notre établissement ces dix dernières années. Elle a comme objectif de familiariser les radiologues avec les pathologies kystiques du pelvis chez le fotus sur la base d'une IRM, qui prend de plus en plus d'importance dans l'imagerie de dépistage anténatale, de prouver son utilité et d'offrir des points d'enseignement pratiques qui permettraient de limiter le diagnostic différentiel.

Dans cette étude nous avons distingué dans le pelvis fotal 3 espaces anatomiques sur un plan sagittal, plan le plus relevant en IRM : antérieur, moyen et postérieur pour les fœetus de sexe féminin et antérieur et postérieur pour ceux de sexe masculin. Chez un fœetus physiologique, l'espace antérieur contient la vessie pour les deux sexes, l'espace moyen contient l'utérus pour ceux de sexe féminin et le postérieur, le rectum pour les deux sexes. Comme les espaces anatomiques du pelvis fotal sont souvent difficilement reconnaissables, nous suggérons qu'en cas d'anomalie kystique, de rechercher l'éventuel déplacement des organes pelviens engendré par effet de masse. L'algorithme que nous suggérons est 1: déterminer le sexe du fœtus. 2: identifier l'espace anatomique dans lequel la pathologie est localisée. 3: analyser les caractéristiques sémiologiques de l'anomalie afin de préciser son origine.

Concernant l'origine de l'anomalie kystique, elle pourrait être associée à une dilatation excessive d'une structure anatomique déjà présente (p.e. hydrocolpos, vessie dilatée sur valves urétrales postérieures), versus de vraies malformations congénitales kystiques ou des tumeurs (p.ex. duplication vaginale sur cloaque, tératome sacrococcygien).

Nous avons identifié les pathologies kystiques pelviennes les plus fréquentes en relation avec l'espace anatomique ainsi que les renseignements complémentaires qu'une IRM fotale apporte en comparaison avec l'ultrason anténatal. Globalement les pathologies kystiques examinées dans cette thèse sont les suivantes: LUTO*, anomalies de l'ouraque, syndrome $\mathrm{MMIH}^{* *}$, rein multi kystique ectopique, anomalies utérines, vaginales, cloaque, kyste de duplication rectal, tératome sacrococcygien, méningocèle antérieur, kystes ovariens, malformations lymphatiques.

Les caractéristiques IRM et épidémiologiques de chaque pathologie sont étudiées séparément et illustrées avec des images IRM de notre département.

Cette étude apporte des preuves que l'IRM fœtale est une méthode d'imagerie complémentaire très utile notamment pour les cas compliqués ou non conclusifs. L'algorithme et l'analyse des espaces anatomiques que nous proposons pourraient s'avérer des très bons outils de diagnostic et d'enseignement pour de jeunes radiologues.

*LUTO, low urinary tract obstruction; **MMIH, megacystis-microcolon-intestinal hypoperistalsis 


\title{
Magnetic resonance imaging of fetalpelvic cysts
}

\author{
Styliani Archontaki $\odot,{ }^{1,2}$ Yvan Vial, ${ }^{3}$ Sylviane Hanquinet, ${ }^{4}$ Reto Meuli, ${ }^{1}$ Leonor Alamo ${ }^{1}$ \\ ${ }^{1}$ Department of Diagnostic and Interventional Radiology, University Hospital of Lausanne (CHUV), Rue du Bugnon, 46, Lau- \\ sanne 1011, Switzerland \\ ${ }^{2}$ Department of Radiology, Hospital of Yverdon, Rue d'Entremonts 11, Yverdon-les-Bains 1400, Switzerland \\ ${ }^{3}$ Department of Gynecology and Obstetrics, University Hospital of Lausanne (CHUV), Rue du Bugnon, 46, Lausanne 1011, \\ Switzerland \\ ${ }^{4}$ Department of Pediatric Radiology, University Hospital of Genève (HUG), Rue Willy-Donze'6, Geneva 1205, Switzerland
}

\begin{abstract}
The detection of fetal anomalies has improved in the last years as a result of the generalization of ultrasound pregnancy screening exams. The presence of a cystic imaging in the fetal pelvis is a relatively common finding, which can correspond to a real congenital cystic lesion or result from the anomalous liquid accumulation in a whole pelvic organ, mainly the urinary bladder, the uterus, or the vagina. In selected cases with poor prognosis and/or inconclusive echographic findings, magnetic resonance may bring additional information in terms of the characterization, anatomical location, and real extension of the pathology. This pictorial essay describes the normal pelvic fetal anatomy, as well as the most common pelvic cysts. It also describes the causes of an anomalous distension of the whole pelvic organs detected in utero, with emphasis on prenatal magnetic resonance imaging exams. Moreover, it proposes practical teaching points to reduce the differential diagnosis of these lesions based on the sex of the fetus, the division of the pelvis in anatomical spaces, and the imaging findings of the pathology. Finally, it discusses the real utility of complementary MRI.
\end{abstract}

Key words: Prenatal diagnosis-Fetal MRI-

Congenital cysts-Pelvic pathology

Abbreviations

GW Gestational week

MRI Magnetic resonance

imaging

US

Ultrasound
The detection of fetal anomalies has continuously improved over the last two decades as a result of the generalization of prenatal ultrasound (US) screening exams. A pelvic pathology accounts for about $10 \%$ of all fetal problems detected [1], and it often presents a cystic appearance at imaging. In these cases, the most common diagnosis can be divided into two main groups: the first one corresponds to real congenital cystic lesions while the second group results from the anomalous accumulation of liquid in a whole pelvic fetal organ, mainly the bladder, the vagina, and/or the uterus, mostly due to a distal obstruction. The pathologies most commonly detected in utero are listed in Table 1 . US is clearly the most relevant imaging method for diagnosis, but in selected cases, complementary prenatal magnetic resonance imaging (MRI) may bring additional information in terms of the characterization, anatomical origin, and evaluation of the real extension of the pathology.

This pictorial essay intends to familiarize radiologists with the wide spectrum of fetal pelvic cystic pathology, and evaluates the role of prenatal MRI exams, based on representative examples from our own experience in the last 10 years. Moreover, it proposes practical teaching points to reduce the differential diagnosis of these lesions based on the sex of the fetus, the location of the pathology regarding the anatomical pelvic spaces, and the imaging findings of the lesion.

This paper was presented as an electronic poster at the European Congress of Radiology (ECR), Vienna 2014. C-1788: “Cystic masses and pseudomasses in the fetal pelvis: a differential diagnosis based on fetal MRI findings'.

Correspondence to: Leonor Alamo; email: Leonor.alamo@chuv.ch 


\section{Imaging of the normal fetal pelvis}

The fetal bladder should be visible at US in all fetuses after the 12th week of pregnancy (w.p) [1,2]. After this moment, the normal bladder is never completely empty, even immediately after voiding [3]. It is well identifiable as a round or ovoid structure, filled with urine, homogeneously hypoechoic at US, and hypointense on T1(T1-W) and hyperintense on T2-weighted (T2-W) MR images. The bladder wall should be smooth, with a thickness $<3 \mathrm{~mm}[2,4]$, whereas the normal urethra is usually not seen at imaging. The umbilical arteries should be visualized on both sides of the bladder and help to identify this organ.

The correct identification of the normal external genitalia at imaging depends mainly of the timing of the exam during pregnancy and the position of the fetus during the exam [4]. Concerning the internal genitalia in females, the vagina is usually not recognizable, but the uterus and especially the ovaries are often seen at exams performed at late pregnancy, due to the organs stimulation by placental and maternal hormones $[5,6]$.

The production of meconium usually occurs after the 13th week of pregnancy. At approximately the 20th week of pregnancy, a gradual increase of anal sphincter pressure leads to a progressive accumulation of meconium in the distal bowel, colon, and rectum [7]. The small bowel and colon are difficult to differentiate from each other at US exams. On the contrary, they are easily identifiable at
MRI, because of the different protein concentrations and signal intensities of the fluids filling the proximal bowel-hypointense on T1-W and hyperintense on T2-W images - and the colon and rectum-meconium, hyperintense on T1-W and hypointense on T2-W images [1].

\section{Anatomical pelvic spaces}

At MRI, the most relevant imaging plane for diagnosis is the midline sagittal plane. In this plane, the pelvis can be divided into different anatomical spaces (Fig. 1). In females, there are three spaces: the anterior one is limited dorsally by the posterior bladder wall and contains the urine bladder. The middle space, located between the bladder and the ventral wall of the rectum, contains the internal genital organs, vagina and uterus. Finally, the posterior space contains the rectum and the presacral fat. In males, the pelvis can be mainly divided into two spaces: the anterior one contains the urine bladder, prostate, and urethra, whereas the posterior space contains the rectum and the presacral fat. The middle space with the recto-vesical pouch is practically a virtual space, and it is usually not identifiable at imaging.

A clear distinction of these anatomical spaces is extremely difficult at prenatal imaging. However, in the presence of a pelvic pathology, the displacement of the pelvic organs may help to identify the pelvic space at which the pathology origins, limiting the differential diagnosis. As previously described, the different signal

Table 1. Most common prenatally diagnosed main pelvic cystic pathologies related to the fetal pelvic spaces. Ovarian cysts and lymphatic malformations do not respect the anatomical spaces

\begin{tabular}{lll}
\hline Anterior space & \multicolumn{1}{c}{ Middle space } & Posterior space \\
\hline LUTO & Ectopic multicystic kidney & Rectal duplication cyst \\
Urachus anomalies & Uterine anomalies & Sacrococcygeal teratoma \\
MMIH syndrome & Vaginal anomalies & Anterior meningocele \\
& Cloaca & \\
& Enteric duplication cyst & \\
\hline
\end{tabular}

LUTO, low urinary tract obstruction; MMIH, megacystis-microcolon-intestinal hypoperistalsis
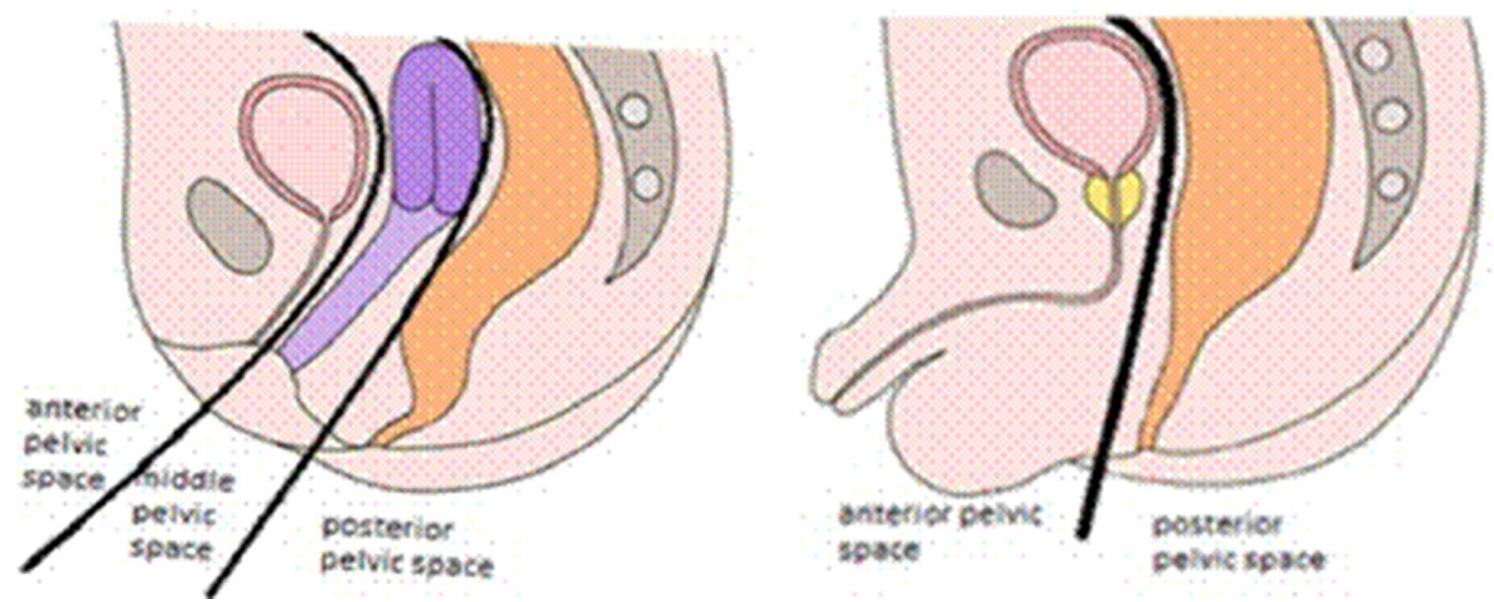

Fig. 1. Division of the pelvis in anatomical spaces in females and males. 
intensities of the urine and meconium at MRI allow an easy identification of the bladder and rectum at the midline sagittal plane. The displacement of these two organs can be used as a guide to locate the origin of the pathology. A pathology arising from the anterior space would cause a posterior displacement of the rectum, a pathology arising from the middle space would displace the bladder ventrally and the rectum dorsally, and, finally, a pathology arising from the posterior space would cause a ventral displacement of the rectum. Table 1 describes the location of the main pelvic pathologies related to the anatomical spaces. However, there are some exceptions: lymphatic malformations do not respect the anatomical spaces; ovarian cysts may be observed not only in the pelvis but also in the fetal abdomen and meconium cysts, and pseudocysts may have a variable location.

\section{Diagnostic approach to a cystic pelvic pathology detected in utero}

Three steps are essential to guide the diagnosis:

1. To identify the sex of the fetus.

2. To recognize the pelvic space in which the lesion origins.

3. To analyze the imaging findings of the pathology.

\section{Pathology in the anterior pelvic space}

A megacystis is the most frequently observed pathology in this space. The pathologic distension of the bladder is usually secondary to a distal obstruction of the urethra and may be associated or not to a distended urachus.

The term LUTO results from the acronym of fetal lower urinary tract obstruction and includes a wide variety of pathologies. The most important causes are the posterior urethral valves, the prune belly syndrome, the urethral stenosis, and the urethral atresia. Less common causes include anterior urethral valves or diverticulum, prolapsed ureterocoele, megalourethra, and megacystismicrocolon-intestinal hypoperistalsis syndrome [8]. Posterior urethral valves account for the great majority of lower urethral obstructions. They are observed exclusively in males and have an incidence of 1:8000-25,000 births [2]. The main findings are the detection of a variable, often extremely distended, thick-walled bladder, and of significant hydroureteronephrosis, usually bilateral. However, hydroureteronephrosis can be asymmetrical, and up to $15 \%$ of patients present only unilateral dilatation [9]. A dilated posterior proximal urethra is often observed, showing a typical morphology, classically known as "the keyhole sign"” (Fig. 2). Severe megacystis is often associated with oligohydramnios and may lead to abnormal renal function. In fetuses with a poor prognosis, percutaneous vesicoamniotic shunting can be used to relieve urinary tract obstruction [10].
Postnatal treatment consists of the immediate placement of a bladder catheter, followed by surgical ablation of the valves.

In general, a distended bladder is easily identifiable at US studies and MRI is rarely required. However, we perform prenatal MRI in selected severe cases in order to evaluate the fetal lungs as a severe megacystis may cause elevation of the hemidiaphragms, chronic bilateral lung compression, and secondary pulmonary hypoplasia. These findings may be aggravated in the presence of the often associated oligohydramnios that also contributes to the lung hypoplasia by three mechanisms: the extrinsic compression of the fetus, a reduction of the fetal breathing movements, and a limited pulmonary distension. In these patients, as occurred in patients with congenital diaphragmatic hernia referred for the routine evaluation of fetal lungs $[11,12]$, the obtained lung volumes can be compared with those of the normal fetuses at the same age of pregnancy in order to evaluate the severity of the hypoplasia and to predict the postnatal outcome (Table 2).

The megacystis-microcolon-intestinal-hypoperistalsis, also known as MMIH syndrome, is a rare condition of unknown etiology, characterized by a massively dilated urine bladder, incomplete intestinal rotation, microcolon, and small bowel dilation. Ascites can also be observed. It occurs almost exclusively in females, which helps to differentiate it from other forms of lower urinary tract obstruction. Imaging findings include megacystis and bilateral hydronephrosis, typically without oligohydramnios [2, 13]. The microcolon may be difficult to identify at US but is usually well distinguished at T1-W MRI images because of the typical high signal intensity of the protein-rich meconium (Table 2).

Urachus anomalies are occasionally detected in utero. There is no consensus about the normal timing for urachal obliteration in fetal life. The failure of urachal obliteration can give rise to patent urachus (48\%), urachal cysts $(31 \%)$, urachal sinus $(16 \%)$, and vesicourachal diverticulum $(5 \%)$ [14, 15]. A patent urachus is often associated with a low urethral obstruction and with umbilical cord cysts. At imaging, it is seen as a longitudinal, tubular structure connecting the anterior part of the bladder dome with the umbilicus (Fig. 2).

\section{Pathology in the middle pelvic space}

Pathologies in this space are mainly observed in females and related to uterine and/or vaginal anomalies. They cause anterior displacement of the bladder and posterior displacement of the rectum at the midline sagittal plane. Isolated hydrocolpos/hydrometrocolpos is very uncommon, with a reported incidence of $1: 16,000$ in newborn girls. It results from a distal obstruction with accumulation of reproductive secretions at the vagina and/or uterus. Imperforated hymen, midline vaginal 

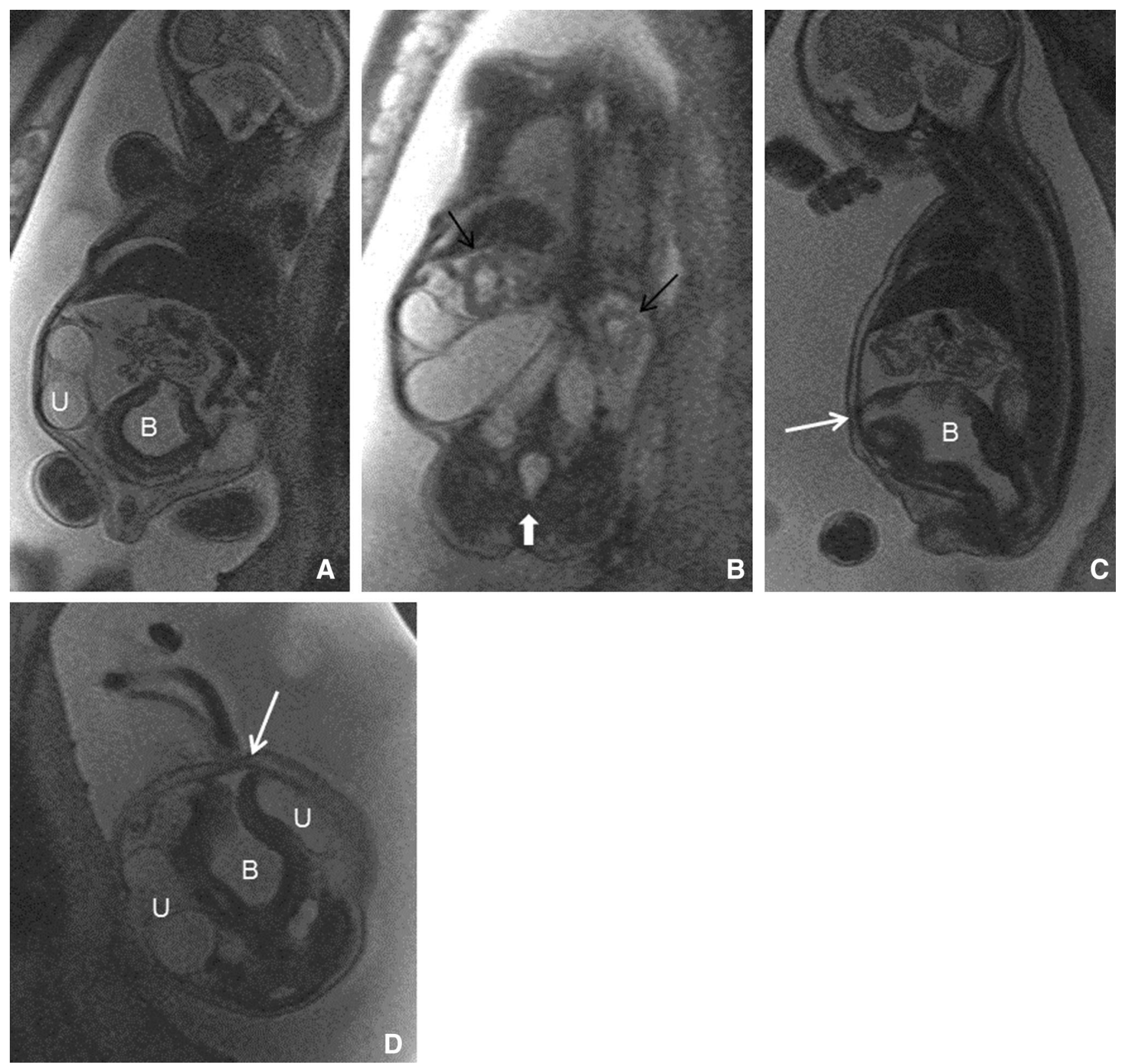

Fig. 2. Lower urinary tract obstruction: posterior urethral valves and patent urachus in a male fetus. Coronal $(A, B)$, sagittal (C), and axial (D) T2-W MR images at the 25th p.w. show the distended urine bladder $(B)$ with a thick, irregular wall. Note the urine ascites, a "keyhole" appearance of the dilated proximal urethra (B white block arrow) and a patent

septum and vaginal atresia are the most frequently observed causes [16-18] (Fig. 3). Severe hydrocolpos/hydrometrocolpos may produce unilateral or bilateral hydronephrosis. Prenatal diagnosis occurs mostly at late gestation. The distended, fluid-filled vagina usually shows a typical pear-inversed form, with a recognizable uterus on top that may or not be distended [18]. Diagnosis at US is not always evident. At MRI, the different signal intensities of the urine present in the bladder and urachus (white arrows C and D). There is severe bilateral hydronephrosis with extremely dilated ureters $(U)$ and reduced size of the kidneys (black arrows B). Note the cranial displacement of both hemidiaphragms and the resulting severe bilateral pulmonary hypoplasia.

of the genital secretions filling the uterus/vagina may suggest the diagnosis (Table 2).

Cloaca is an extremely rare malformation with an incidence of 1:50,000 females [19]. It results from the failure of the urorectal septum to join the cloacal membrane at the early embryonic development [20], and is often associated to multisystemic anomalies. Cloaca can lead to bladder obstruction, hydrometrocolpos, and/or colonic dilatation, and it is often associated with genital 


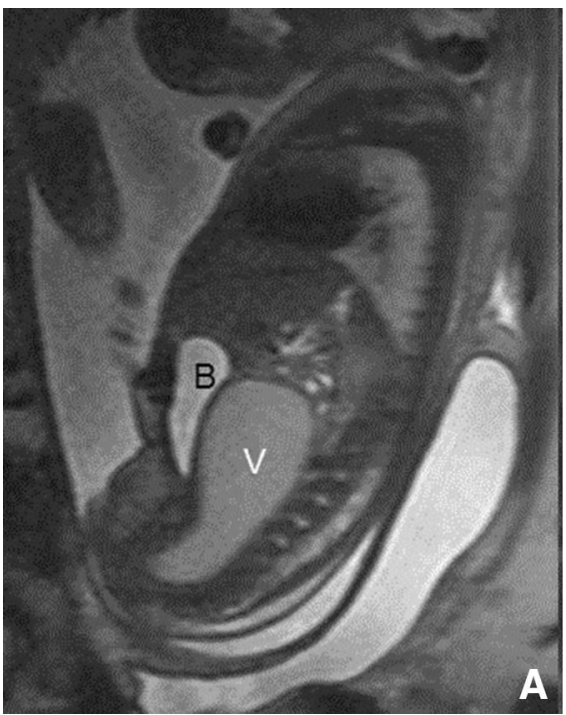

Fig. 3. Imperforated hymen in a female fetus. Sagittal T2-W (A) and T1-W (B) and axial T2-W (C) MR images at the 35th w.p. show a retrovesically located, fluid-filled structure that corresponds to a distended vagina $(\mathrm{V})$. Note the different signal intensities of the fluid filling the bladder and the vagina.
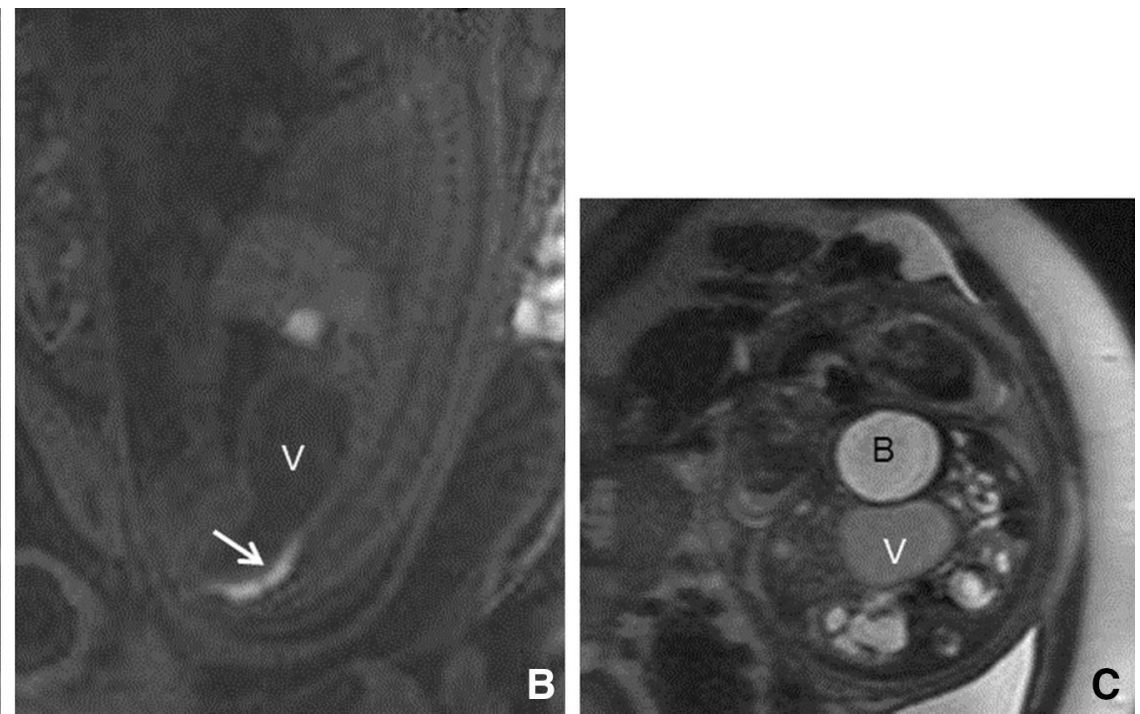

The suggested US diagnosis was cloaca. There is ventral displacement of the bladder (B) and secondary bilateral hydronephrosis (C). Observe the posterior displaced and compressed rectum, (B white arrow) filled with protein-rich meconium.

Table 2. Possible additional information obtained at MRI studies related to the US exams for some cystic pathologies in the fetal pelvis

Possible additional information at MRI

LUTO/urachus anomalies

MMIH syndrome

Utero/vaginal anomalies

Cloaca

Duplication cysts

Sacrococcygeal teratoma

Lymphatic malformation
Repercussion over the renal parenchyma, severity of secondary lung hypoplasia

Better identification of the microcolon

Associated anomalies of the rectum, bladder, and/or genital organs

Associated anomalies of the rectum, bladder, and/or genital organs (genital duplication)

Anatomical relationship of the cyst to the intestinal/rectal wall

Classification of the tumor, pelvic extension, and detection of complications

Extension of the lesion, detection of complications (hemorrhage), and detection of complications

LUTO, low urinary tract obstruction; MMIH, megacystis-microcolon-intestinal hypoperistalsis

duplication (Fig. 4). Its diagnosis in utero is extremely difficult. Indeed, most cases are only confirmed after birth in the presence of a single common perineal opening for the genital, urinary, and gastrointestinal tracts. Occasionally, US and/or MRI may recognize the associated genital duplication and suggest the diagnosis. In some cases, an identical signal intensity of the fluids filling the urinary, genital, and digestive cavities at MRI suggests communication of the three systems and can help to establish diagnosis (Table 2).

Ectopic kidneys are observed in 1:900 autopsies. Most of them are located in the pelvis, posterior to the urine bladder. They often present anomalous ureteral implantation with distal obstruction that can produce a secondary multicystic renal dysplasia [21]. Pelvic located multicystic dysplastic kidneys can be extremely heterogeneous at imaging and therefore difficult to identify in utero (Fig. 5). However, the absence of one of the kidneys in its normal location should suggest the diagnosis.

Enteric duplication cysts result from the failure of the intestinal lumen to recanalize during embryogenesis. They have an incidence of about 1:10,000 births and are most frequently located in the ileum.
They can communicate or not with the intestinal lumen [7, 2224]. At imaging, enteric cysts appear as an elongated, tubular or spherical unilocular cyst, in contact to the bowel. The wall of the duplication cyst is typically thick and multilayered. Prenatal MRI may help to con- firm the anatomical contact between the cyst and the bowel.

\section{Pathology in the posterior pelvic space}

Pathologies arising from the posterior pelvic space usually cause anterior displacement of the rectum at the midline sagittal images.

Rectal duplication cysts are extremely rare and constitute only about $4 \%$ of all enteric cysts [7, 22-24]. They are found in contiguity with the meconium-filled rectum and present the same imaging findings as previously described for the enteric cysts, including the typical thick, multilayered wall and the homogeneous intracystic fluid signal. Rectal duplication cysts have been extremely seldom discovered at prenatal studies (Fig. 6). 


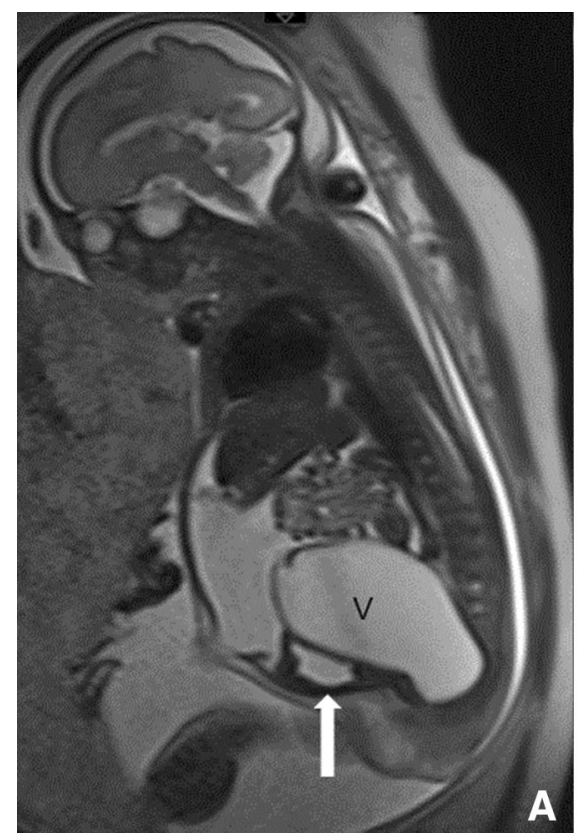

Fig. 4. Cloaca with complete genital duplication in a female fetus. Sagittal T2-W (A) and T1-W (B) and axial T2-W (C) MR images at the 30th w.p. show the fluid-filled, distended vagina (V). The bladder is displaced anteriorly (white block arrow A, $B$ ) and the rectum is not seen. Note that the meconium-filled sigmoid is displaced cranially (B). There is severe ascites, bilateral hydronephrosis with small kidneys (arrows, C), and a

Diagnostic confirmation is only possible after resection and requires the identification of digestive lining epithelium. They are usually removed after birth, even in asymptomatic pa- tients, in order to avoid late complications such as ulceration, bleeding, infection, or perforation.

Sacrococcygeal teratoma is the only cystic tumoral lesion observed in the fetal pelvis. The teratoma is the most common congenital tumor, with a reported incidence of 1:35,000-40,000 births, and the fetal pelvis is the most frequent location [25] (Fig. 7). Teratomas are typically heterogeneous at imaging because of the different components and the presence of necrosis, cystic degeneration, hemorrhages, and/or calcifications [26]. Their prognosis depends mainly on their size and their location. The Altmann classification distinguishes four types of sacrococcygeal teratomas regarding their location: Primarily exophytic or type I, observed in $47 \%$ of cases and having the best prognosis; type II, dumbbell shaped with equivalent extra- and intrapelvic size masses and present in about $34 \%$ of cases; type III with a larger intrapelvic component and present in $9 \%$ of cases; and type IV, entirely intrapelvic, present in $10 \%$ of cases and having the worst prognosis [27]. Fetal MRI is often performed in these patients and may provide relevant information concerning the real extension of the tumor and/or its effects over the adjacent organs, especially in intrapelvic tumors types Altmann III and IV (Table 2).
Anterior sacral meningoceles result from the anterior herniation of sacral meninges secondary to hypoplastic sacral vertebral segments. They are often observed as part of the Currarino triad or in conditions with prominent dural ectasia [20]. The best diagnostic clue at imaging is the identification of a homogeneous cystic presacral mass communicating with the thecal sac through an anterior sacral defect [5].

\section{Pathologies with variable anatomical location}

Ovarian cysts are often observed in female fetuses at US performed in late pregnancies. The fetal ovaries are extremely mobile and may be observed not only in the pelvis, but also in the fetal abdomen. Ovarian cysts should be considered the first possible diagnosis in the presence of a pelvic or abdominal cyst in a female fetus. Most of them are simple functional cysts, resulting from excessive stimulation of the fetal ovaries by the placental and maternal hormones $[5,6]$. Simple cysts are anechoic, uniocular or multilocular, with fine internal septations [28], and they rarely develop complications. Large, "'wandering", cysts have an increased risk of torsion and hemorrhage in utero. In these cases, they present internal echoes, hemorrhagic areas, fluid-fluid levels, and/or thickened septa. The natural course of ovarian cysts is a spontaneous, slow postnatal regression. However, 

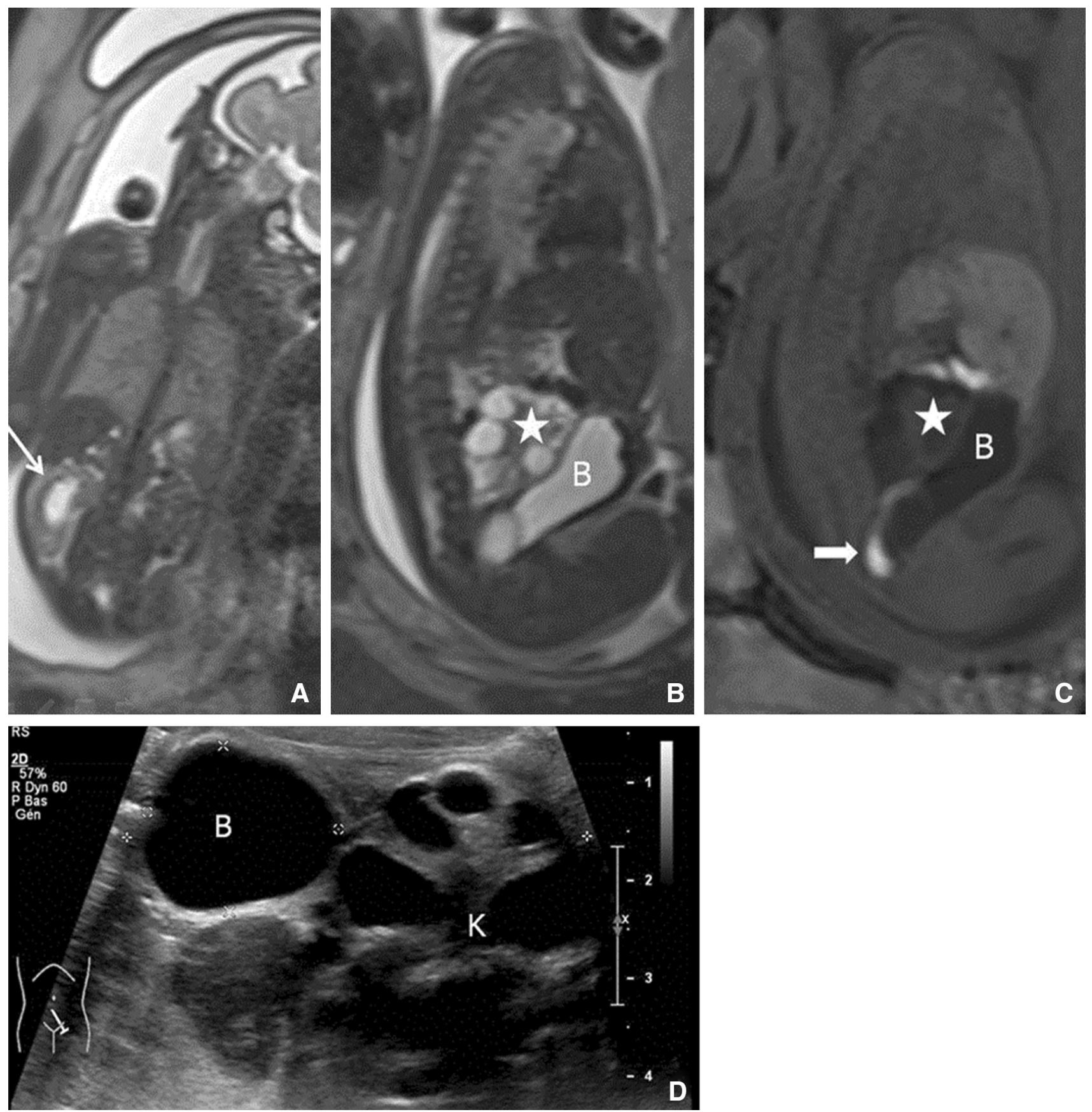

Fig. 5. Multicystic dysplastic pelvic kidney in a female fetus. Coronal T2-W (A) MR image at 28th w.p. shows a slightly dilated right kidney (white arrow). The left kidney is not seen in its normal position. Sagittal T2-W (B) and T1-W (C) MR images show a retrovesically located, heterogeneous lesion with multiple different sized cysts, corresponding to the ec-

surgical resection may be required in voluminous cysts or in the case of torsion and/or hemorrhage $[5,28]$. Complementary prenatal MRI is rarely performed, but can be useful in selected complicated cases (Fig. 8).

Lymphatic malformations Mesenteric cysts are unilocular lymphatic malformations. They are usually topic located dysplastic left kidney (star). The bladder (B) is displaced anteriorly $(C)$ whereas the rectum is displaced caudally. Prenatal US suggested a sacrococcygeal teratoma. Note that the presacral space is normal. Neonatal axial US image (D) confirms the left retrovesically located multicystic kidney (K).

asymptomatic, have a small size, and are mostly located in the mid-abdomen. Large malformations are usually multilocular, with multiple internal septations [29]. They do not respect the anatomical spaces and can be present everywhere in the body, with the posterior cervical triangle as the most common location (Fig. 9). Lymphatic 

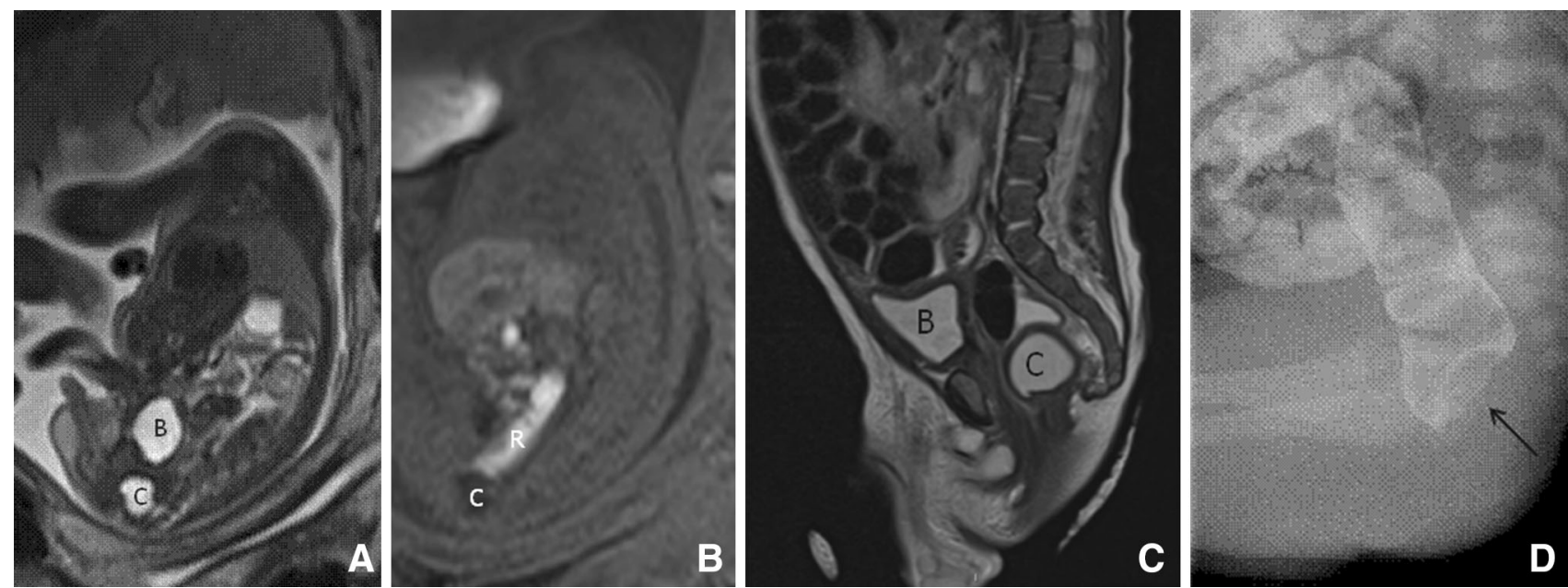

Fig. 6. Rectal duplication cyst in a male fetus. Sagittal T2-W (A) and T1-W (B) MR images at the 30th w.p. show the welldefined, homogeneously fluid isointense cystic lesion (C), with a thick wall. The lesion is located posterior to the rectum $(R)$, filled with protein-rich, hyperintense meconium at T1-W MR image (B) (B, bladder). Postnatal sagittal (C) T2-W MR ima-

ges at day 4 shows the cyst in contact to the rectum wall, with a well-defined thick wall, characteristic for bowel duplication. Lateral view of contrast enema at day 4 (D) reveals the mass effect at the posterior rectum wall (black arrow). Diagnosis was confirmed at pathology after surgical excision.
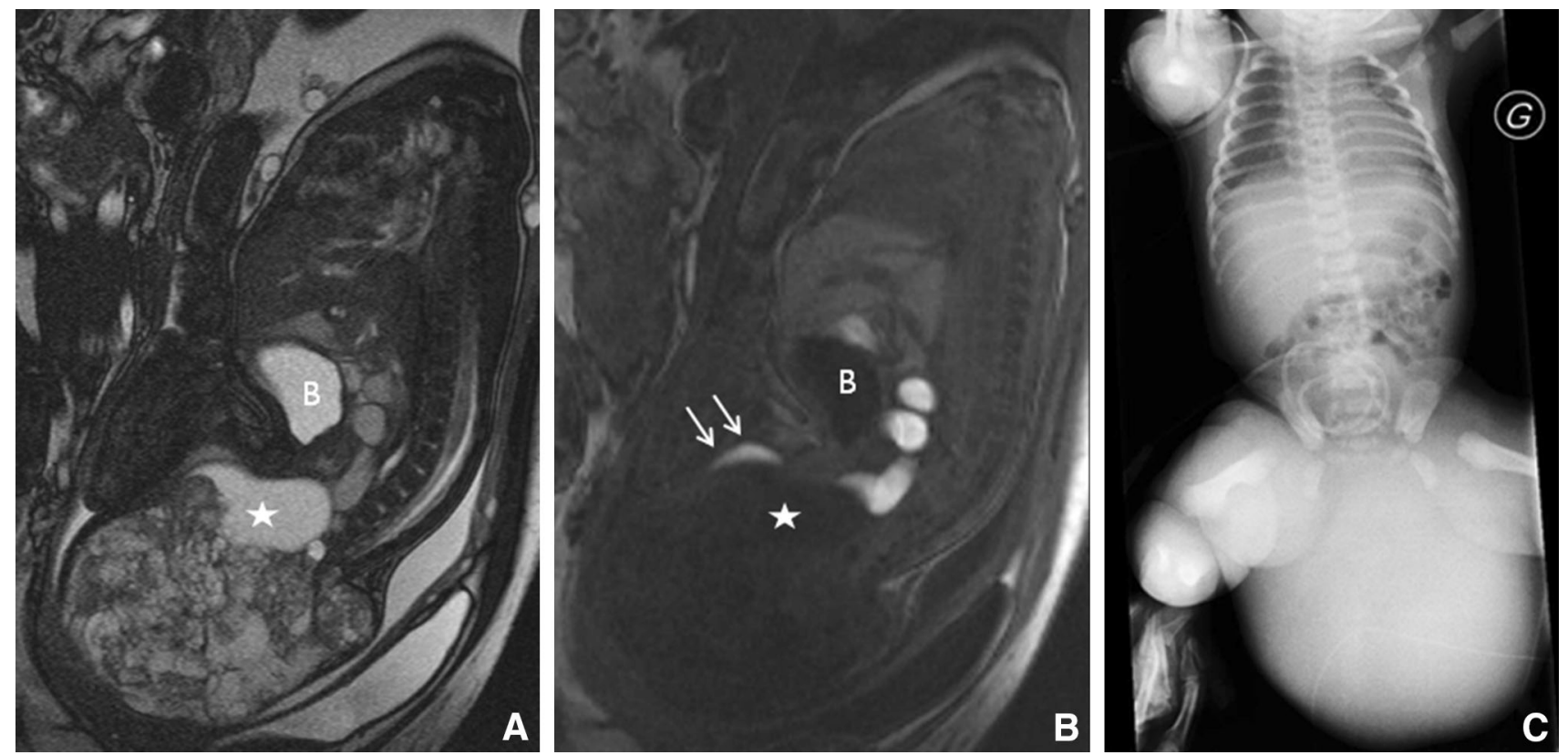

Fig. 7. Sacrococcygeal teratoma in a female fetus. Sagittal T2-W (A) and T1-W (B) MR images at the 36th p.w. show the voluminous, mainly exophytic congenital tumor-Altmann Iwith both cystic and solid components. Note the anatomical

malformations can rapidly increase in size in the case of hemorrhage or infection. After bleeding, fluid/fluid levels are often observed at imaging. In voluminous lesions, MRI helps to define the real anatomical extension of the malformation and its effects on the adjacent organs (Table 2). relationship with the coccyx and the anterior and cranial displacement of the rectum (white arrows B). Postnatal babygram shows the huge tumoral mass. Note the distortion of the pelvic bones and the secondary bilateral hip dysplasia.

Finally, meconium peritonitis is a sterile chemical peritonitis secondary to intestinal perforation in utero with subsequent extravasation of the meconium into the peritoneal cavity. The reported prevalence is 1:30,000 live births with mortality ranging between 11 and 50\%. Meconium peritonitis may produce both meconium cysts 

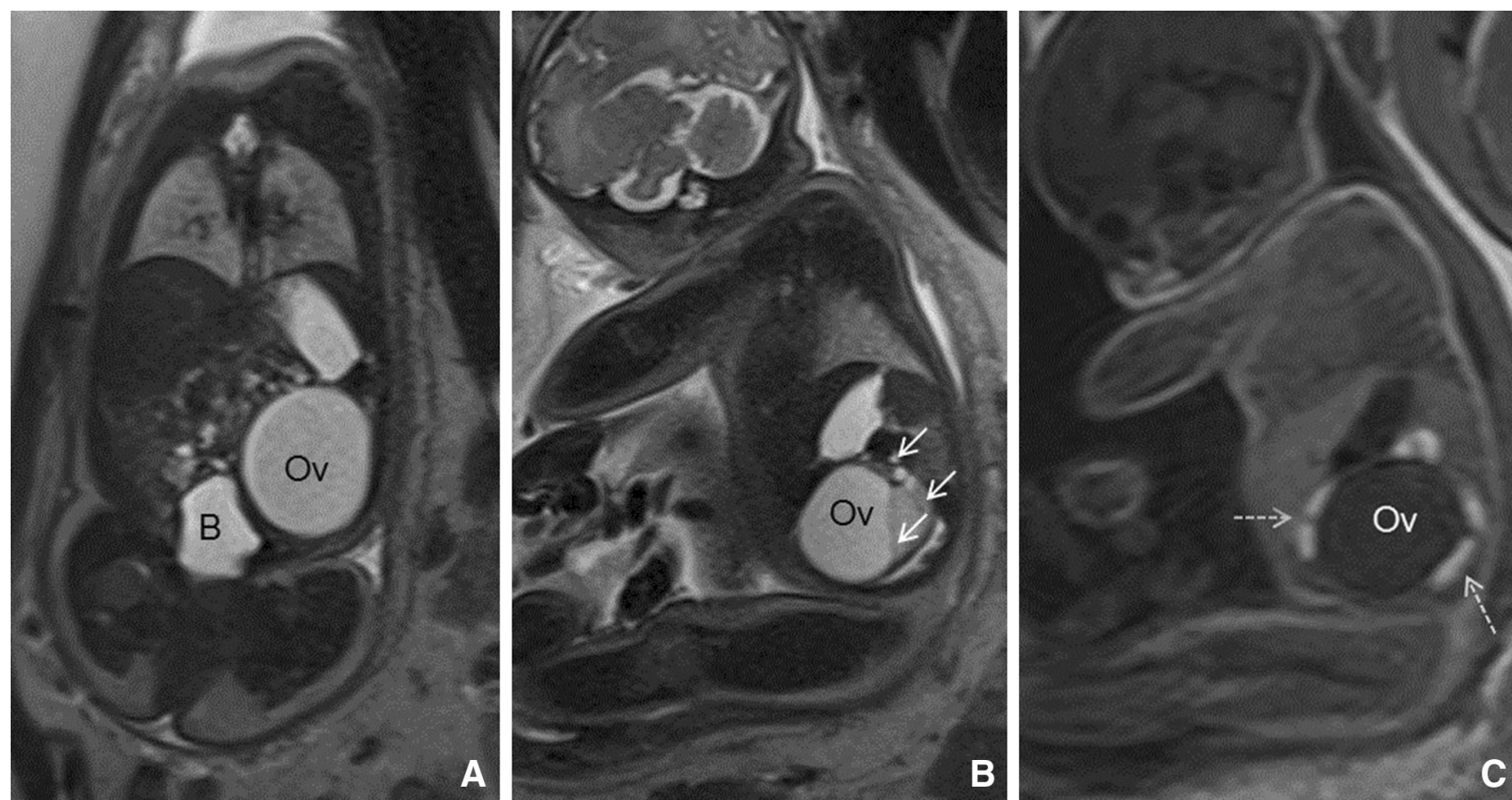

Fig. 8. Ovarian cysts. Fetal MRI was performed after detection of a left voluminous, rapidly increasing in size, complex cyst at prenatal US. The coronal $(A)$ and sagittal (B) T2-W MR images (30th GW.) show the ovarian cyst (C) in the left hemiabdomen. Note the internal septations and the
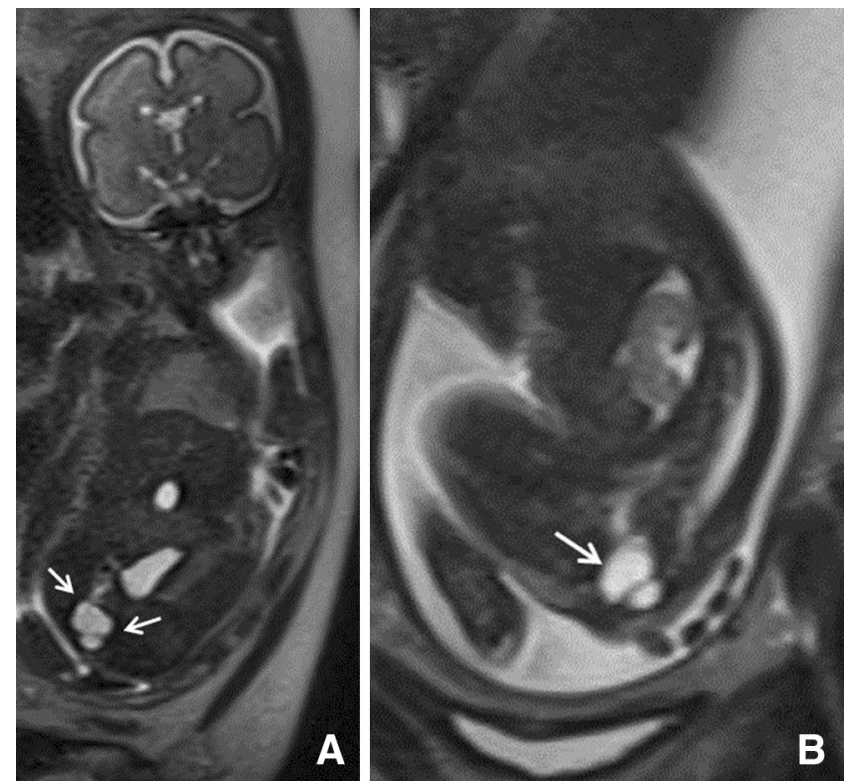

Fig. 9. Lymphatic malformation in a male fetus. The coronal (A) and sagittal (B) T2-W MR images at the 26th p.w. show a cystic mass with internal septations in the posterior pelvic space, presacral located (white arrow). A cystic sacrococcygeal teratoma-Altmann IV-was suggested at both US and MRI studies. The patient was operated upon after birth and a lymphatic malformation was diagnosed at pathology. normal ovarian tissue, peripherally located (white arrows B). The meconium-filled colon is displaced by the enlarged ovary (black arrows C). B, bladder; Ov, ovary. The cysts reduced progressively after birth.

when the extravasation of meconium occurs in a peritoneal cavity and produces a fibrous wall and/or meconium pseudocysts, resulting from a thinning intestinal wall, in which the muscle layer of the wall remains continuous with the intestine but lost its epithelium because of the persistent inflammation [30]. Prenatal MRI is rarely performed in these cases and can not differentiate between cysts and pseudocysts.

The advantages and the possible additional information obtained at complementary MRI in fetuses with pelvic cystic pathology are shown in Table 2 .

\section{Conclusion}

The detection of a pelvic cyst or of an anomalous distension of a whole pelvic organ at a US screening exam during pregnancy is relatively common and can be observed in a wide spectrum of pathologies. In most cases, US is sufficient to establish the diagnosis. However, an additional prenatal MRI is occasionally performed in selected cases with poor prognosis and/or inconclusive echographic findings. The method offers multiplanar capacity, a high anatomical definition, and allows an accurate distinction of the pelvic organs due to the different chemical composition of the fluids filling the bladder, the small bowel, and the colon. The displacement of these organs helps to identify the anatomical space at which the pathology origins, limiting the differential diagnosis. 
Funding No funding was received for this study.

Conflict of interest The authors declare that they have no conflict of interest.

Ethical approval This article does not contain any studies with animals performed by any of the authors. All the MRI and US image files were anonymized.

Informed consent Statement of informed consent was not applicable since the manuscript does not contain any patient data.

\section{References}

1. Levine D (2005) Atlas of fetal MRI. Boca Raton: CRC Press

2. Chauvin NA, Epelman M, Victoria T, Johnson AM (2012) Complex genitourinary abnormalities on fetal MRI: imaging findings and approach to diagnosis. AJR 199:222-231

3. McHugo J, Whittle M (2001) Enlarged fetal bladders: etiology, management and outcome. Prenat Diagn 21:958-963

4. Martin C, Darnell A, Duran C, et al. (2004) Magnetic Resonance Imaging of the intrauterine fetal genitourinary tract: normal anatomy and pathology. Abdom Imaging 29:286-302

5. McEwing R, Hayward C, Furness M (2003) Foetal cystic abdom inal masses. Australas Radiol 47:101-110

6. Sakala EP, Leon ZA, Rouse GA (1991) Management of antenatally diagnosed fetal ovarian cysts. Obstet Gynecol Surv 46:407-414

7. Saguintaah M, Couture A, Veyrac C, Baud C, Quere MP (2002) MRI of the fetal gastrointestinal tract. Pediatr Radiol 32:395-404

8. Farrugia MC (2016) Fetal outbladder outlet obstruction: embryopathology, in utero intervention and outcome. J Pediatr Urol . doi:10.1016/j.jpurol.2016.05.047

9. Williams CR, Perez LM, Joseph DB (2001) Accuracy of renal bladder ultrasonography as a screening method to suggest posterior urethral valves. J Urol 165:2245-2247

10. Morris RK, Malin GL, Quinlan-Jones E, et al. (2013) Percutaneous vesicoamniotic shunting versus conservative management for fetal lower urinary tract obstruction (PLUTO): a randomised trial. Lancet 382:1496-1506

11. Ward VL, Nishino M, Hatabu H, et al. (2006) Fetal lung volume measurements: determination with MR imaging-effect of various factors. Radiology 240:187-193

12. Wedner M, Hagelstein C, Debus A, et al. (2014) MRI based ratio of fetal volume to fetal body volume as a new prognostic marker in congenital diaphragmatic hernia. AJR 202:1330-1336

13. Tuzovic L, Anyane-Yeboa K, Mills A, Glassberg K, Miller R(2014) Megacystis-microcolon-intestinal hypoperistalsis syndrome: case report and review of prenatal ultrasonographic findings. Fetal Diagn Ther 36:74-80

14. Yu JS, Kim KW, Lee HJ, et al. (2001) Urachal remnant diseases: spectrum of CT and US findings. Radiographics 21:451-461

15. Fuchs F, Picone O, Levaillant JM, et al. (2008) Prenatal diagnosis of a patent urachus cyst with the use of 2D, 3D, 4D ultrasound and fetal magnetic resonance imaging. Fetal Diagn Ther 24:444-447

16. Picone O, Laperelle J, Sonigo P, et al. (2007) Fetal magnetic res- onance imaging in the antenatal diagnosis and management of hydrocolpos. Ultrasound Obstet Gynecol 30:105-109

17. Yildirim G, Gungorduk K, Aslan H, et al. (2008) Prenatal diagnosis of imperforate hymen with hydrometrocolpos. Arch Gynecol Obstet $278: 483-485$

18. Gupta P, Sharma R, Kumar S, et al. (2010) Role of MRI in fetal abdominal cystic masses detected on prenatal sonography. Arch Gynecol Obstet 281:519-526

19. Calvo-Garcia MA, Kline-Fath BM, Levitt MA, et al. (2011) Fetal MRI clues to diagnose cloacal malformations. Pediatr Radiol 41:1117-1128

20. Alamo L, Meyrat BJ, Meuwly JY, Meuli RA, Gudinchet F (2013) Anorectal malformations: finding the pathway out of the labyrinth. RadioGraphics 33:491-512

21. Meizner I, Yitzhak M, Levi A, et al. (1995) Fetal pelvic kidney: a challenge in prenatal diagnosis? Ultrasound Obstet Gynecol 5:391-393

22. McNamara A, Levine D (2005) Intraabdominal fetal echogenic masses: a practical guide to diagnosis and management. Radio- graphics 25:633645

23. Sharma S, Yadav AK, Mandal AK, et al. (2015) Enteric duplications cysts in children: a clinicopathological dilemma. J Clin Diagn Res 9(8):EC08-EC11. doi:10.7860/JCDR/2015/12929.6381

24. Arraiza M, Metser U, Vajpeyi R, et al. (2015) Primary cystic peritoneal masses and mimickers: spectrum of diseases with pathologic correlation. Abdom Imaging 40:875-906

25. Alamo L, Beck-Popovic M, Gudinchet F, Meuli R (2011) Con- genital tumors: imaging before life begins. Insights Imaging 2:297-308

26. Danzer E, Hubbard AM, Hedrik HL, et al. (2006) Diagnosis and characterization of fetal sacrococcygeal teratoma with prenatal MRI. AJR 187:350-356

27. Altmann RP, Randolph JG, Lilly JR (1974) Sacrococcygeal teratoma: American Academy of pediatrics surgical section sur- vey-1973. J Pediatr Surg 9:389-398

28. Bryant AE, Laufer MR (2004) Fetal ovarian cysts: incidence, diagnosis and management. J Reprod Med 49:329-337

29. Kollipara R, Dinneen L, Rentas KE, et al. (2013) Current classification and terminology of pediatric vascular anomalies. AJR 201:1124-1135

30. Minato M, Okada T, Miyagi H, et al. (2012) Meconium pseudocyst with particular pathology findings: a case report and review of the literature. J Pediatr Surg 47:E9-E12 



\section{ANNEXE}

The diagnosis of pelvic cystic lesions and/or anomalously fluid-filled pelvic whole organs detected in utero is challenging because of the difficulties to identify the anatomical origin of these lesions. The objective of this study was to develop a guide to improve their final diagnosis, based on imaging findings at MRI studies. We retrospectively identified all patients with a prenatal diagnosis of pelvic cystic lesions or distension of pelvic whole organs detected at prenatal exams in our institution between 2007 and 2013 ( $\mathrm{n}=21$ patients) and with a final diagnosis obtained from autopsy $(n=5)$, pathological exams after surgery $(n=3)$ and/or postnatal imaging studies $(n=13)$. The final diagnosis of these patients is described in Table 1.

\begin{tabular}{|c|c|}
\hline PATHOLOGY & NUMBER OF PATIENTS \\
\hline LUTO/PUV & 2 \\
\hline LUTO/PUV + patent urachus & 3 \\
\hline Pelvic multicystic dysplastic kidney & 2 \\
\hline $\begin{array}{c}\text { Hydrometrocolpos } \\
\text { (Imperforated hymen) }\end{array}$ & 2 \\
\hline Cloaca & 1 \\
\hline Rectal duplication cysts & 6 \\
\hline Sacrococcygeal teratomas & 1 \\
\hline Ovarian cysts & 1 \\
\hline Lymphatic malformations & \\
\hline
\end{tabular}

Table 1.- Pathologies observed in this series and number of patients presenting with each pathology.

The prenatal imaging studies of these patients at US and MRI exams were reviewed and the imaging findings compared with the final diagnosis. All MRI studies were performed in a 1,5 Tesla system after the $20^{\text {th }}$ week of gestation. The used MR protocol is described in Table 2. The sequences were performed in all three spatial fetal planes. 


\begin{tabular}{|c|c|c|c|c|c|c|}
\hline & $\begin{array}{c}\text { Slice thickness } \\
(\mathbf{m m})\end{array}$ & TR (msec) & $\begin{array}{c}\text { TE } \\
(\mathbf{m s e c})\end{array}$ & Angle & FOV & Matrix \\
\hline T2-HASTE & $5 \mathrm{~mm}$ & 999 & 88 & 135 & $350 \times 350$ & $307 \times 512$ \\
\hline T2-TRUE FISP & $5 \mathrm{~mm}$ & 6,44 & 3,22 & 70 & $350 \times 262.5$ & $230 \times 512$ \\
\hline T1-VIBE & $4 \mathrm{~mm}$ & 3,69 & 1,6 & 12 & $255 \times 340$ & $192 \times 256$ \\
\hline
\end{tabular}

Table 2. Fetal MRI protocol used in our institution

The review of the MRI studies revealed that the best planes for analyzing the fetal pelvic anatomy were the axial plane at the level of the bladder and specially the midline T1- and T2-W sagittal plane. In these planes and with this method, it was relatively easy to identify both the fetal bladder, filled with urine homogeneously hyperintense on T2-W and hypointense on T1-W images- and the rectum-sigmoid, filled with meconium, hyperintense on T1-W and hypointense on T2-W MR images.

In the midline sagittal plane in normal males, the pelvis can be divided into two main compartments. The anterior pelvic space (APS) contains the genito-urinary organs and is limited dorsally by the posterior wall of the urine bladder whereas the posterior pelvic space (PPS) contains the rectum, the presacral fat and the sacrum. The anatomical division of the pelvis in normal male fetuses is shown in Fig. 1a.

In normal female fetuses, at the same midline sagittal plane, the pelvis can be divided into three anatomical spaces: the APS, containing the urine bladder and limited by the posterior wall of the bladder; the middle pelvic space (MPS), with the internal genital organs (vagina and uterus) and the PPS, containing the rectum, the presacral space and the sacrum. The anatomical division of the pelvis in normal female fetuses is shown in Fig. 1b. 

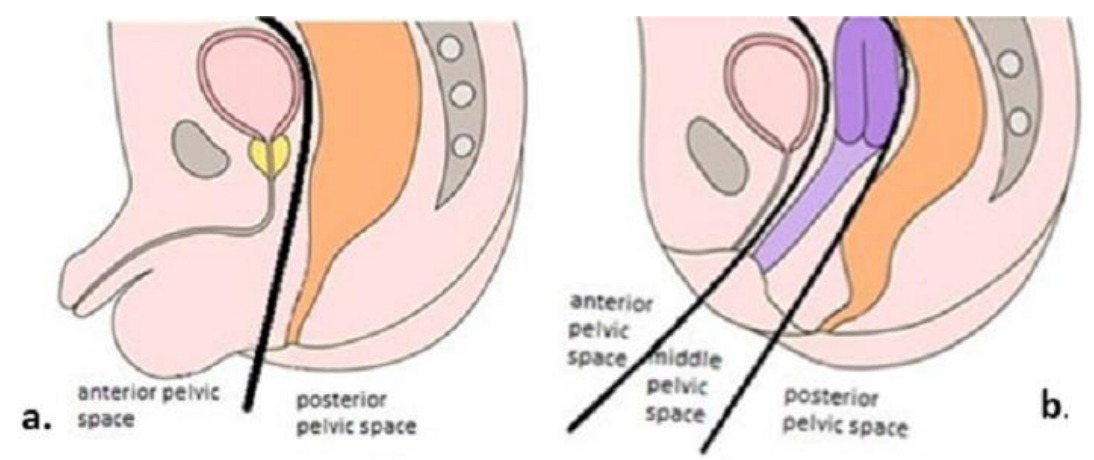

Fig.1.- Anatomical division of the pelvis in male- (a) and female (b) fetuses.

Fig 2 and 3 show the normal pelvic anatomy and the anatomic spaces at the transverse and midline sagittal MRI planes for male and female fetuses, respectively.

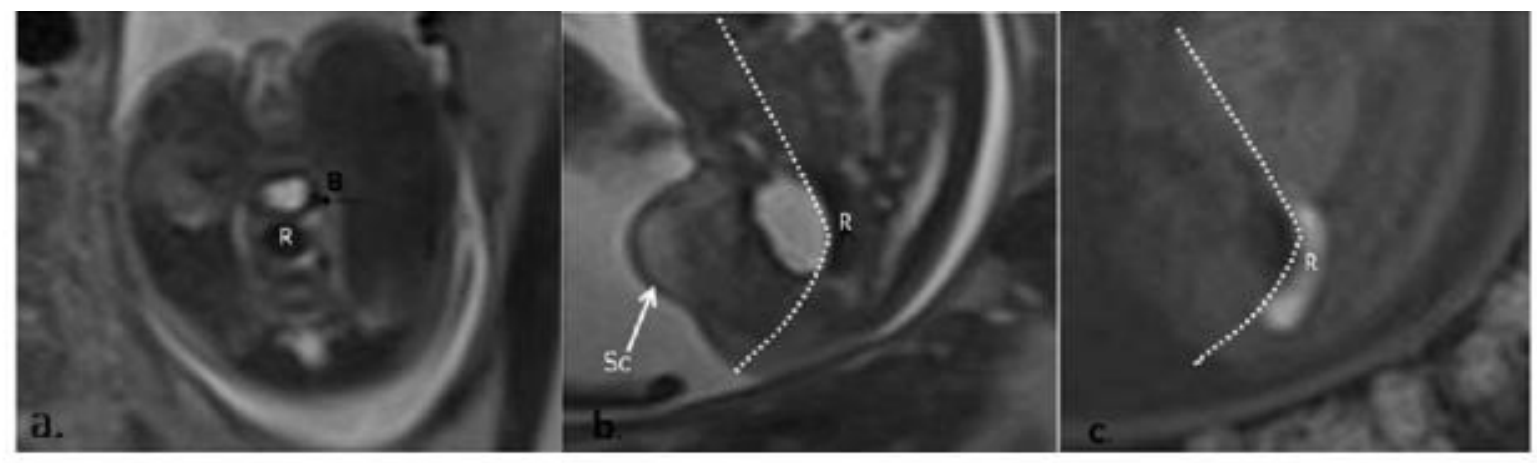

Fig.2. Normal pelvic anatomy in males. Axial T2-W (a) and sagittal T2- (b) and T1-W MR images (c) show the normal anatomy of the pelvis in this male fetus at the 27th pregnancy week The round/oval urine bladder $(B)$ is hyperintense on T2- $(a, b)$ and hypointense on T1-W images (c), whereas the rectum is hyperintense on T1- (c) and hypointense on T2-W images (a, b). Note the clearly identifiable scrotum (Sc, white arrow, b). The white lines separate the anatomical pelvic spaces.

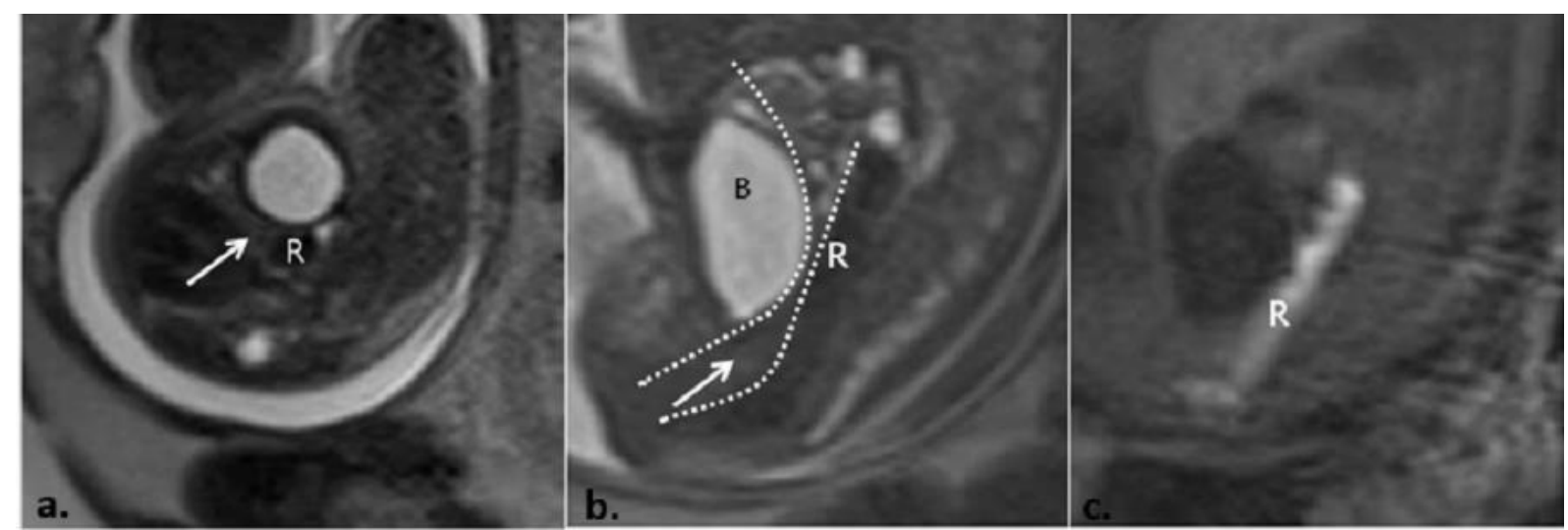

Fig.3 Normal pelvic anatomy in females. Axial T2-W (a) and sagittal T2- (b) and T1-W (c) MR images show the normal anatomy of the pelvis in this female fetus at the 30th pregnancy week. The uterus (white arrows) is seen between the bladder $(B)$ and the rectum $(R)$ (white arrow, $a$ and $b$ ). The round/oval urine bladder is hyperintense on T2- $(a, b)$ and hypointense on T1-W images (c) and the rectum, filled with meconium is hyperintense on T1- (c) and hypointense on T2-W images (a, b). The white lines separate the anatomical pelvic spaces. 
In case of a pelvic pathology, the direction of the displacement of the fetal bladder and/or the rectum at the midline sagittal plane helps recognizing the anatomical space from where the lesion emerges, limiting the differential diagnosis. The exceptions are the lymphatic malformations and the ovarian cysts. Moreover, the usual location of a pelvic multicystic kidney is posterior to the urine bladder, in the MPS. This space is well differentiated in females but only virtual in males. Table 3 describes the location of the main pelvic cystic pathologies related to the anatomical spaces for males and females.

\begin{tabular}{|c|c|c|c|}
\hline & ANTERIOR SPACE & MIDDLE SPACE & POSTERIOR SPACE \\
\hline \multirow[t]{3}{*}{ MALES } & LUTO/PUV & ECTOPIC MULTICYSTIC KIDNEY & RECTAL DUPLICATION CYST \\
\hline & URACHUS ANOMALIES & & SACROCOCCYGEAN TERATOMA \\
\hline & & & ANTERIOR MENINGOCELE \\
\hline \multirow[t]{3}{*}{ FEMALES } & LUTO & CLOACA & RECTAL DUPLICATIONS CYST \\
\hline & URACHUS ANOMALIES & VAGINAL/UTERINE ANOMALIES & SACROCOCCYGEAN TERATOMA \\
\hline & & ECTOPIC MULTICYSTIC KIDNEY & ANTERIOR MENINGOCELE \\
\hline
\end{tabular}

Table 3.- Location of pelvic pathology related to the anatomical pelvic spaces in males and females.

If the pathology arises from the APS, the lesion causes a posterior displacement of the rectum. (Fig. 4). A lesion arising from the MPS causes a ventral displacement of the urine bladder and a posterior displacement of the rectum (Fig 5). Finally, if the lesion arises from the PPS, an anterior displacement of the bladder is seen (Fig.6).
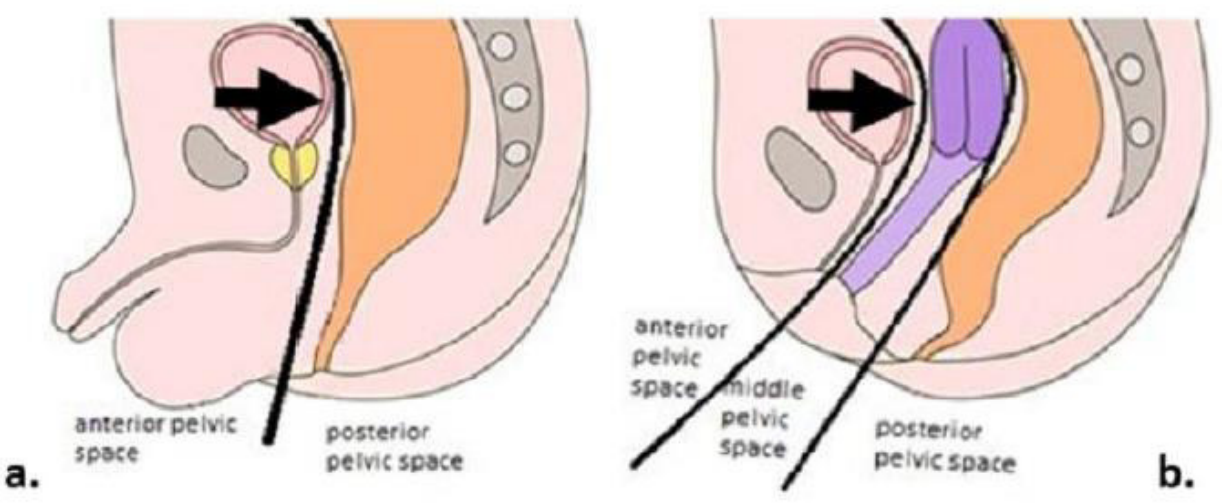

Fig.4 Displacement of the normal anatomical structures in case of pathology arising from the APS in males (a) and females (b). 


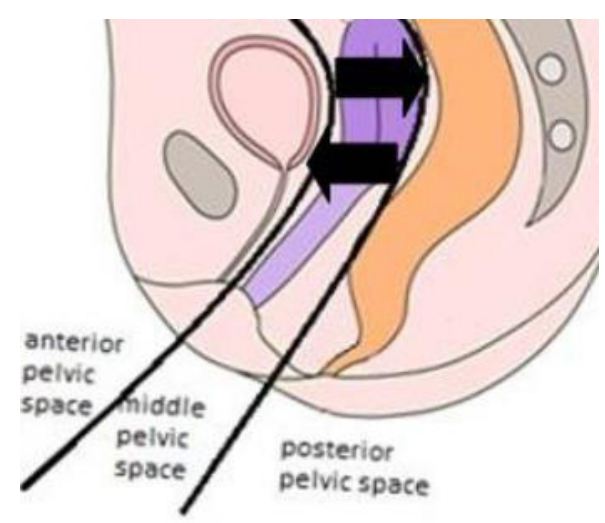

Fig.5. Displacement of the anatomical structures in case of pathology arising from the MPS in females.

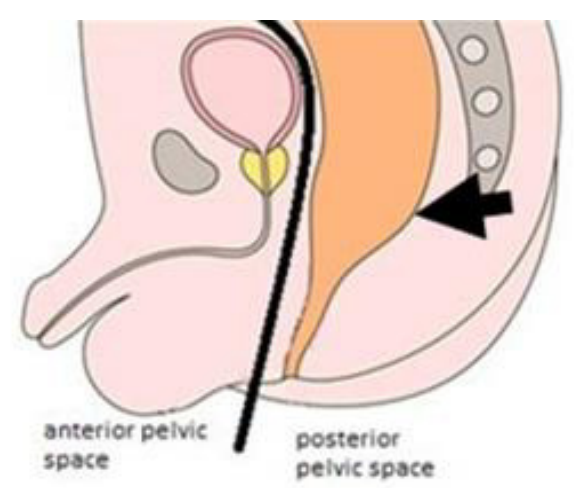

a.

Figure 6.- Displacement of the anatomic structures in case of pathology arising from the PPS in males (a) and females (b).

This series includes 5 patients with pathologies arising from the APS. All of them where males and had a final diagnosis of LUTO (Fetal Lower Urinary Tract Obstruction) caused by posterior urethral valves (Fig. 7). Two of these cases had also a patent urachus. The 5 patients presented a huge distension of the urine bladder megacystis - that caused a posterior displacement of the rectum.

Pathology arising from the MPS was detected in 7 patients. In all cases, the pathology displaced the urine bladder anteriorly and the rectum posteriorly. These displacements were clearly observed at midline sagittal T1- and T2-weighted MRI images (Fig. 8). Anomalous distension of the internal genital organs was detected in 4 female fetuses whereas the remaining 3 fetuses ( 1 male and 2 female) presented an ectopic located, multicystic dysplastic pelvic kidney.

Pathologies arising from the PPS were detected in 9 cases, including 7 sacrococcygeal teratomas, 1 lymphatic malformation and 1 rectal duplication cyst. In all patients, the lesion was presacral located, causing a ventral and cranial displacement of the rectum (Fig 9 and 10). 


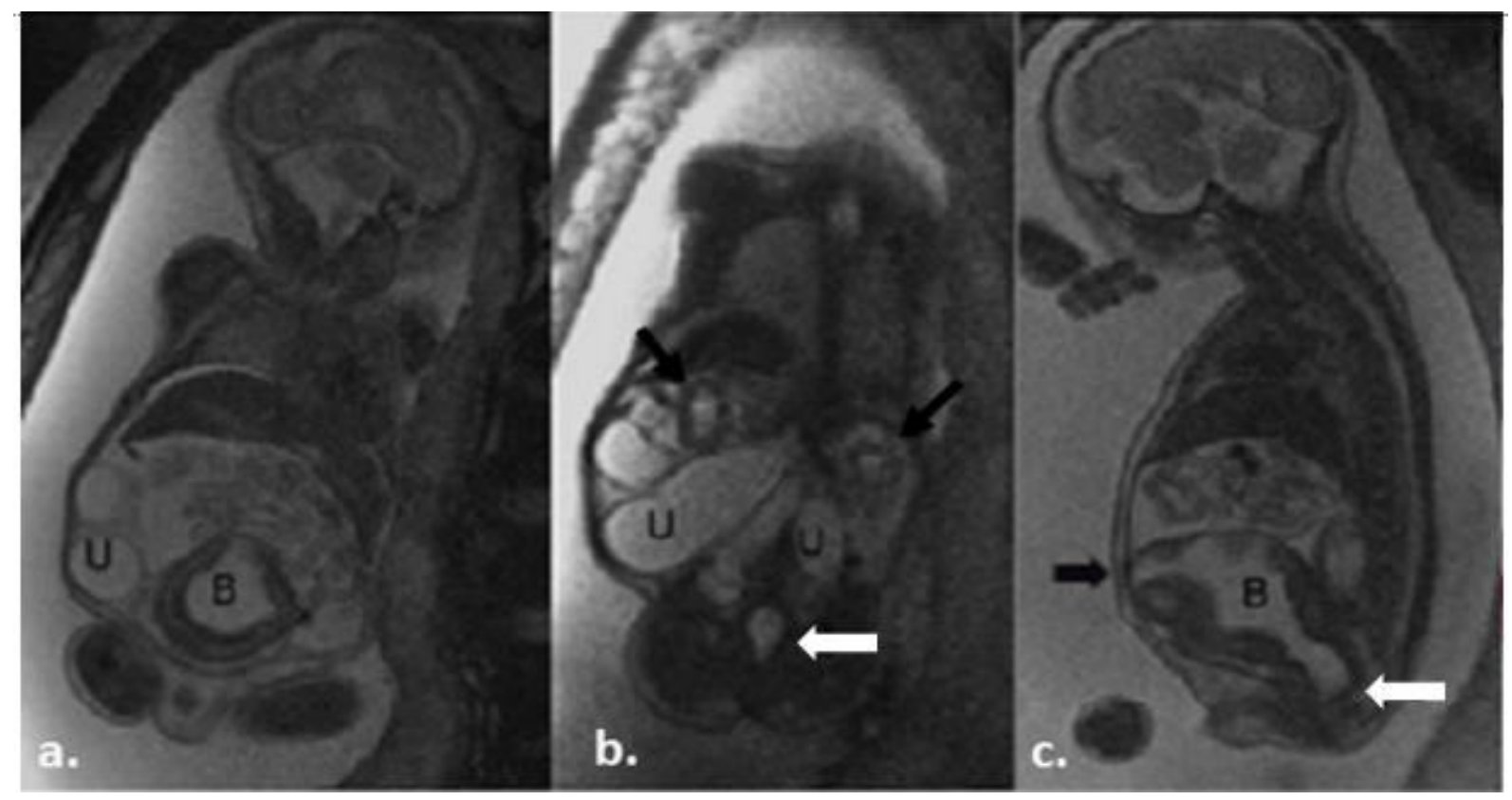

Fig. 7- Posterior urethral valves with patent urachus. Coronal (a and b) and sagittal (c) T2-W MR images at the $25^{\text {th }} \mathrm{GW}$ show the distended urine bladder $(\mathrm{B})$ with thick, irregular wall in this male fetus. Note the dilation and the " keyhole " appearance of the proximal urethra (b and c, white arrow), the urine ascites and the patent urachus (c, black arrow). There is severe bilateral hydronephrosis with extremely dilated ureters $(U)$ and atrophic kidneys (b, black arrows) The rectum is displaced posteriorly by the large urine bladder.

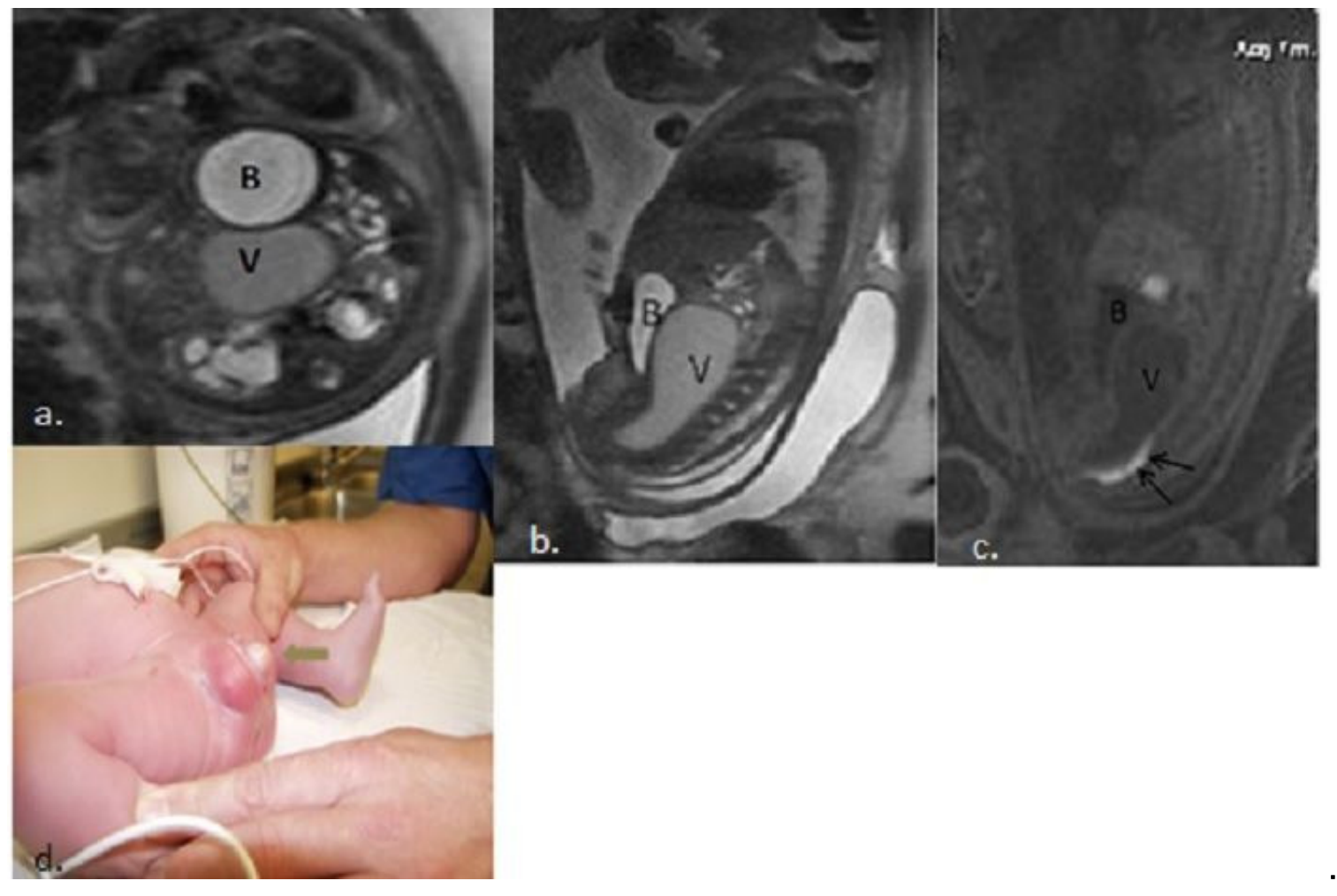

Fig. 8. - Imperforated hymen with secondary hydrocolpos. Axial (a) and sagittal T2-HASTE (b) MR images $\left(35^{\text {th }} \mathrm{GW}\right)$ shows a retrovesical located, homogeneous hyperintense structure, that corresponds to the fluid-filled, distended vagina (V). The difference of the T2 signal intensity between the bladder $(B$ )and the vaginal content shows a different fluid composition. Note the ventral displacement of the bladder (B) and the bilateral hydronephrosis(a).(c) Sagittal T1-W MR image shows 
the posteriorly displaced rectum (black arrow), clearly identifiable because of the hyperintense meconium. (d) Postnatal clinic exam reveals the protrusion of the non-perforated hymen.
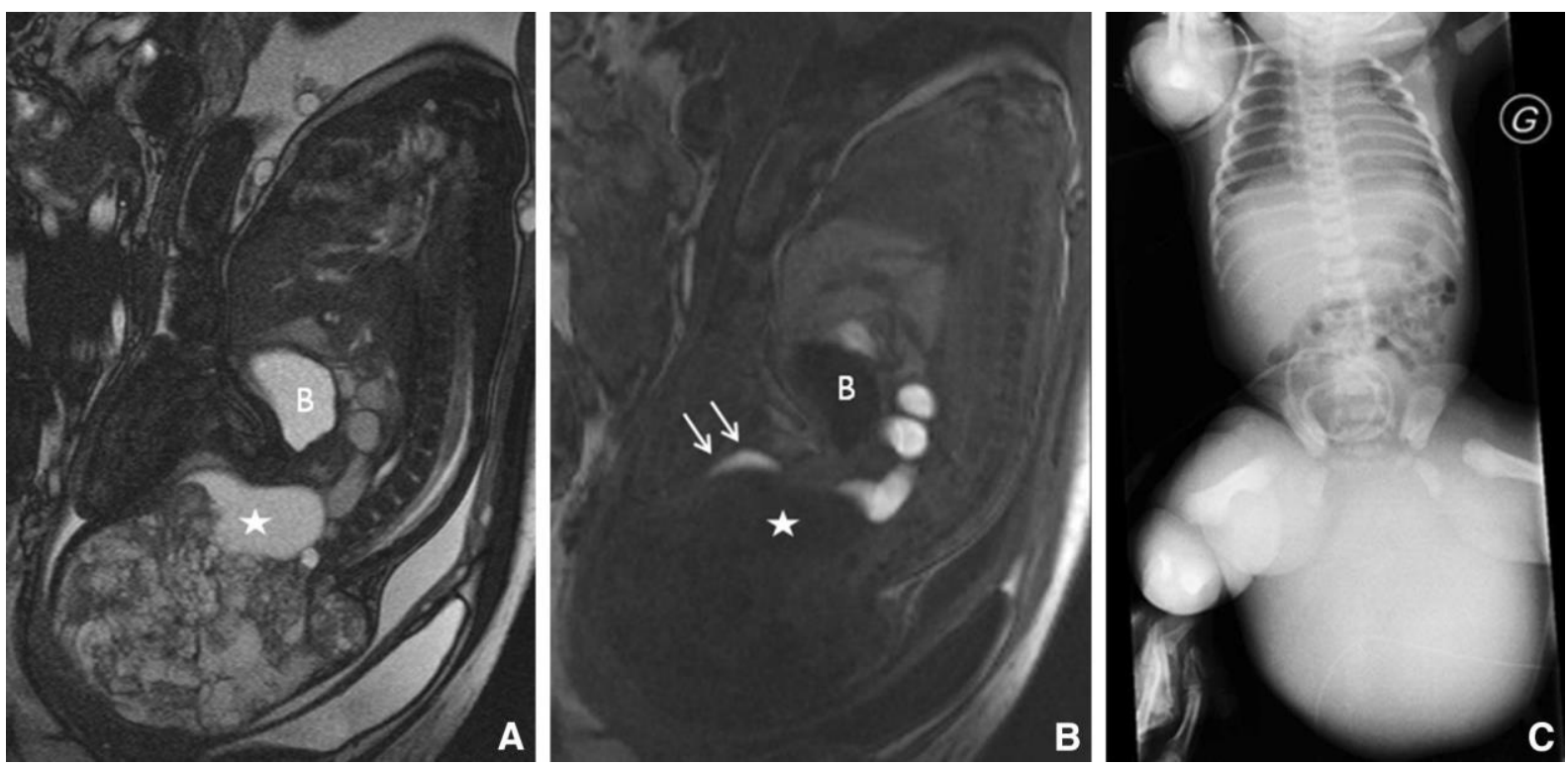

Fig. 9.-Sacrococcygeal teratoma Parasagittal T2-W (a) and T1-W (b) and axial T2-W MR images (c) $\left(36^{\text {th }} \mathrm{GW}\right)$ show the voluminous, heterogeneous tumor and reveals its anatomical relationship with the coxis. The tumor (star), mostly cystic, displaces the bladder (B) cranially (b) and the rectum ventrally (R) (black arrows, c). No intratumoral hyperT1 signal was seen to confirm intratumoral fat. Postnatal babygram shows the huge mass.
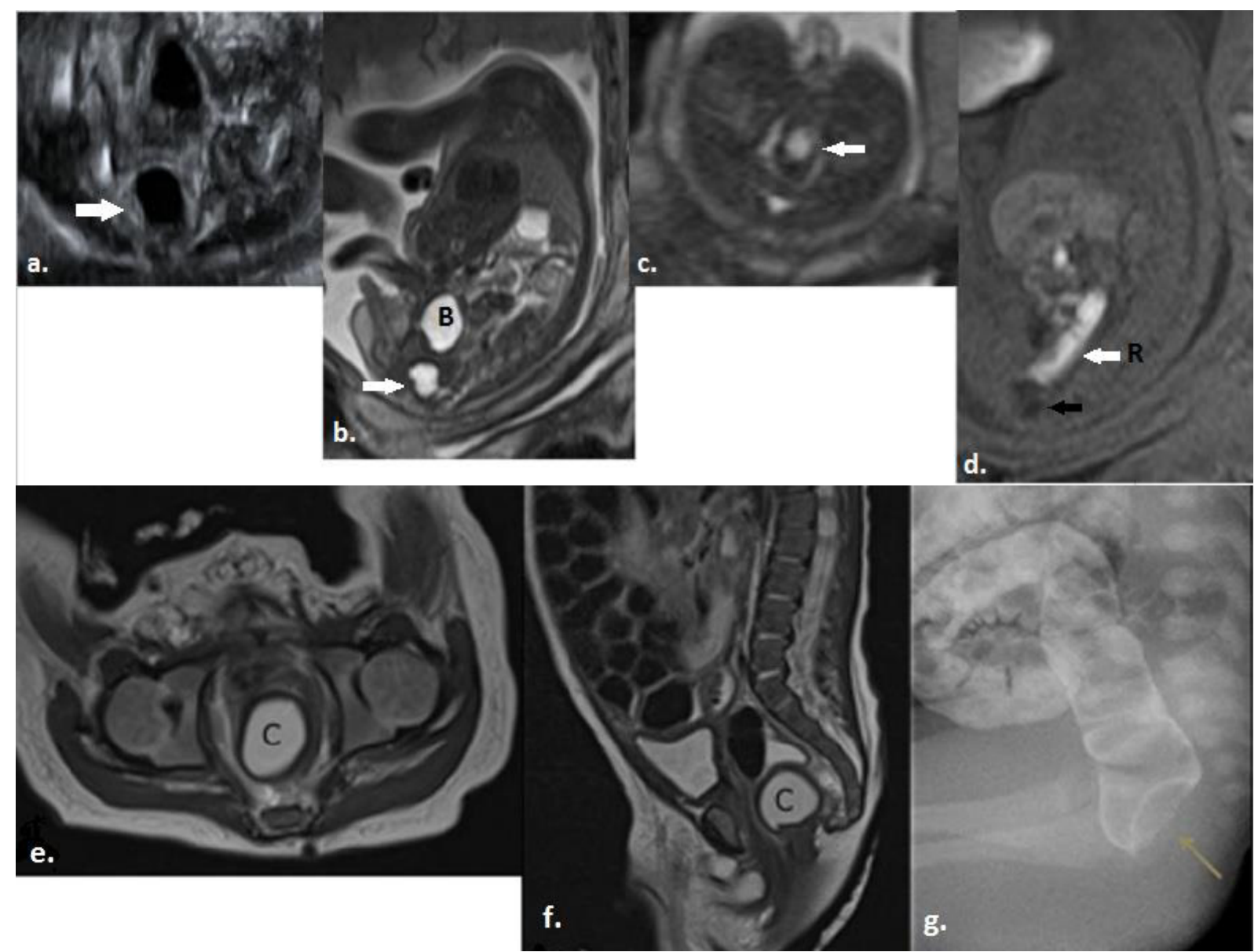
Fig. 10.- Rectal duplication cyst in a male patient. Axial US (a) and sagittal (b) and axial (c) T2-W MR images $(30$ th $w$.) at the level of the ischio-rectal fossae show the well-defined cystic lesion (white arrow), homogeneously anechogenic at US and fluid isointense on T2-W, with thick cyst wall in this male fetus. The bladder (B) is displaced superiorly and the lesion is separated from the coxis (c). Sagittal T1-W (d) MR image shows the cyst (black arrow) located posteriorly to the rectum (R), which is filled with protein rich, hyperintense meconium and displaced cranially. Axial (e) and sagittal (f) T2W MR images at day 4 shows the cyst, located posteriorly to- and exerting a mass effect over the rectum. The cyst wall is well-defined and thick, suggesting bowel duplication and the lesion is clearly separated from the coxis. (g) Lateral view of contrast enema at day 4th reveals the mass effect of the cyst at the posterior wall of the rectum (yellow arrow). Diagnosis was confirmed at pathology.

We concluded that the diagnosis of a pelvic cyst or of an anomalous distension of the pelvic whole organs can be mainly oriented by three main parameters: The sex of the patient, the anatomical space from which the pathology arises and the morphologic characteristics of the lesion. The main lesions observed in each anatomical space in males and females are described in Table 3 whereas Table 4 resumes the final diagnosis, the number of cases and the anatomical location of the lesions detected in this series as well as the additional information provided by complementary MRI.

\begin{tabular}{|c|c|c|}
\hline $\begin{array}{c}\text { PATHOLOGY } \\
\text { NUMBER OF PATIENTS }\end{array}$ & $\begin{array}{l}\text { ANATOMICAL } \\
\text { LOCATION }\end{array}$ & $\begin{array}{l}\text { ADDITIONAL } \\
\text { MRI INFORMATION }\end{array}$ \\
\hline $\begin{array}{l}\text { LUTO/PUV } \\
(3 \text { cases })\end{array}$ & Anterior pelvic space & $\begin{array}{c}\text { Severity of hydronephrosis, repercussion over the } \\
\text { renal parenchyma, severity of secondary lung } \\
\text { hypoplasia }\end{array}$ \\
\hline $\begin{array}{l}\text { LUTO/PUV + patent } \\
\text { urachus } \\
\text { ( } 2 \text { cases })\end{array}$ & Anterior pelvic space & $\begin{array}{l}\text { Severity of hydronephrosis, repercussion over the } \\
\text { renal parenchyma, severity of secondary lung } \\
\text { hypoplasia, detection of patent urachus }\end{array}$ \\
\hline $\begin{array}{l}\text { Ectopic multicystic } \\
\text { dysplastic kidney } \\
\text { (3 cases) }\end{array}$ & Middle pelvic space & $\begin{array}{l}\text { Confirmation of renal ectopia; repercussion over the } \\
\text { contralateral renal parenchyma }\end{array}$ \\
\hline $\begin{array}{l}\text { Hydrometrocolpos } \\
\text { (Imperforated hymen) } \\
(2 \text { cases })\end{array}$ & Middle pelvic space & $\begin{array}{l}\text { Associated anomalies of the rectum, bladder and/or } \\
\text { genital organs }\end{array}$ \\
\hline $\begin{array}{l}\text { Cloaca } \\
(2 \text { cases })\end{array}$ & Middle pelvic space & $\begin{array}{l}\text { Associated anomalies of the rectum, bladder and/or } \\
\text { genital organs }\end{array}$ \\
\hline $\begin{array}{l}\text { Rectal duplication cysts } \\
\text { (1 case) }\end{array}$ & Posterior pelvic space & $\begin{array}{l}\text { Anatomical relationship to the rectal wall, morphology } \\
\text { of the cyst wall }\end{array}$ \\
\hline $\begin{array}{l}\text { Sacrococcygeal teratomas } \\
\text { (6 cases) }\end{array}$ & Posterior pelvic space & $\begin{array}{l}\text { Classification of the tumor, anatomical extension, } \\
\text { detection of complications }\end{array}$ \\
\hline $\begin{array}{l}\text { Ovarian cysts } \\
\text { (1case) }\end{array}$ & Abdomen and pelvis & Detection of complications (hemorrhage) \\
\hline $\begin{array}{l}\text { Lymphatic malformations } \\
\text { ( } 1 \text { case })\end{array}$ & Abdomen and pelvis & $\begin{array}{l}\text { Extension of the lesion, detection of complications } \\
\text { (hemorrhage), repercussion over the adjacent organs }\end{array}$ \\
\hline
\end{tabular}


Table 4.- Resume of the cases in this series, including the final diagnosis, the number of patients presenting each pathology and the description of the additional information provided by the complementary MRI studies comparing to the ultrasound. 